\title{
COMMUNICATION
}

\section{THE RECOVERY OF FIELDS OF VISION IN CONCUSSION INJURIES OF THE OCCIPITAL CORTEX}

\author{
BY \\ M. L. Hine (Capt. R.A.M.C.), \\ LONDON.
}

IT is not very frequently that the opportunity has occurred, even during the present war, of making daily examinations of the visual fields of patients with recent occipital injuries during the period of recovery, as it is rarely that there have been the leisure, the inclination, the perimeter, the suitable patient, and convenient surroundings at the same time. It is obvious that cases of concussion must have been seen best in France, or elsewhere, rather than in England, as, by the time a patient has reached the latter, he has either recovered and there is only the history to go upon, or, if the lesion is more persistent, there is probably no accurate record of his visual fields during the earlier stage of recovery.

For this reason, very largely, at the last meeting of the Ophthalmological Society, S. A. Kinnier Wilson was only able to report on one case which fulfilled in any way his criterion of a concussion injury of the occipital cortex, viz., a lesion tending to recovery which does not result in a permanent hemianopia in any of its varieties, and excluding all cases of head wounds resulting in more or less permanent organic visual defects. And even this single patient seems to have been a very doubtful case, and did not recover in the way one has now come to expect patients with concussion injuries to recover, but, some four or five months after the injury, was left with concentrically contracted fields of vision, showing a well marked helicoid curve of visual fatigue. This patient had had a fracture of the skull in the mid-line by the occipital protuberance and two. fragments of bone had been removed by operation, but the dura apparently had not been penetrated, as no mention is made of this, nor of any subdural haemorrhage having been noted. $\mathrm{He}$ did not come under the care of Kinnier Wilson until two months after the injury, when anything but a gross lesion or a functional condition should have recovered.

It would seem, therefore, to be of general interest to place on record the results I have obtained recently, as during the past few months, in a large Base Hospital Camp in France, I have had the opportunity of watching, during the whole or the greater part of the recovery period, at least five patients, amongst many others with 
head injuries, who had occipital lesions which could be classed under the heading of "concussion injuries," and would seem to satisfy the criterion proposed in the paper mentioned above. A sixth case, which was probably mainly functional, but which in some ways resembles the case quoted by Kinnier Wilson, will also be included in the series. It is obvious that at a Base Hospital, as a rule, it is only the severer concussion or contusion injuries that ofter themselves for examination, and, as in the above mentioned paper, a bruising of the cerebral cortex, which may be of greater or or lesser degree, has been taken to be the pathological basis of the condition known clinically as "concussion."

It is as well to remember, however, that some cases of definitely gross injury to the brain substance may clear up so completely that they are indiscoverable later on, or discoverable only by a very careful examination, and give rise to no subjective symptoms. In this connection a seventh case may well be recorded, as illustrating several of the points to which attention will be directed, although, as there was a small laceration of the brain substance in this patient, it cannot strictly be called a concussion injury.

That the number of cases is not larger is due to several factors. In the first place, many cases of head injury have been, when possible, kept further up the line, at the casualty clearing stations, for some days before evacuation to the base, during which time recovery has to a large extent taken place. Other cases, too, are of so slight a nature that, although there is a definite history of loss of vision to one side, the patient has completely recovered by the time he comes under observation, even though he has not been specially detained.

Then, again, other cases being scattered about in various hospitals and in various wards, under the care of a diversity of medical officers who are constantly changing, either are not brought to one's notice at all, or one is asked to see them when it is too late to detect any alteration in the fields of vision. Thus, I can well remember one patient who had a very definite history of left-sided hemianopia of one day's duration, whom I was asked to see after a week's interval when he had completely recovered, while an officer who was found to have a slight defect of vision in the left inferior quadrant two days after a blow on the occipital region of the skull, had quite recovered when I was asked to see him three days later. And, lastly, it will be seen later how easy it is to miss a recovering lesion unless the examination is made in the slighter cases with a coloured test object.

Of the five patients recorded as cases of concussion injury, three had definite fracture of the skull, and were seen at operation to have either subdural or extradural blood clot, with the dura itself intact. The other two had no demonstrable fracture of the skull, although both had scalp wounds in the occipital region. The 
position of the lesions varied very little as regards their distance from the inion, as can be seen in the diagrams attached to the charts, in which each square represents 1 inch. The condition found in the sixth and seventh cases recorded will be mentioned later.

As brief a description as possible of the cases will now be given, and the comparative charts showing the rate of recovery, while later it will be seen if any conclusions can be drawn from the facts observed. If may be stated that a hand perimeter was used in making the observations, as the patients were, of necessity, in bed ; and, in the first place, the fields were taken with a 10 millimeter white test object. The use of smaller objects and of coloured objects was found very necessary later on, as will be seen. The condition of the patient always precluded a prolonged examination at first, and at no period was it possible to make a very exhaustive investigation, but when possible a few observations were made.with a modified Bjerrum's screen to define more accurately the limits of a macular scotoma.

At the first visit the patient was usually suffering from so much headache, that only two observations were made in each quadrant, when the horizontal and vertical limits of the field had been fixed. In one case (Case 3 ) it was only possible for the same reason to examine the field of one eye, the first time the patient was seen; but, as later the fields in the two eyes were practically symmetrical, it may be assumed that they would have been found so in the first instance. Each patient during his recovery was examined, as far as possible, each day, and any appreciable change recorded. It has only been possible to show the extension of the fields on the various dates on the charts, and these must be read in conjunction with the description of the cases to appreciate the relative vision in the various quadrants. Too prolonged an examination was impossible owing to this proving so tiring to most of the patients; but, as will be seen, I used a roughly accurate method of estimating the progress of recovery, in one suitable case, by using a small coloured test object at varying distances from the eye.

Case 1.- Private A. received a shrapnel wound of the left parietooccipital region just to the left of the middle line, about $1 \frac{1}{2}$ inches above the occipital protuberance, on February 11, and was seen on the morning of the 13 shortly after admission to hospital, when his fields were taken with a $10 \mathrm{~mm}$. white object, on a hand perimeter. The patient had a considerable amount of headache at the time, and it was inadvisable to worry him more than necessary, so only two observations were made in each quadrant, when the vertical and horizontal limits of the fields had been fixed. Subsequently, the fields were recorded at $15^{\circ}$ intervals. The field to the left was found in either eye 
to be a little contracted concentrically. The field to the right in the left eye approached fixation point, but did not quite reach it; while in the right it extended some $15^{\circ}$ further out, showing a similar peaking in the horizontal meridian (Fig. 1). The same afternoon the patient was trephined and a small depressed fracture found. The dura was intact and was not opened, but blood clot was seen beneath; the limits of the haemorrhage not being defined. There was little pulsation when the wound was closed. The optic discs showed slight blurring of the margins, but no measurable swelling.

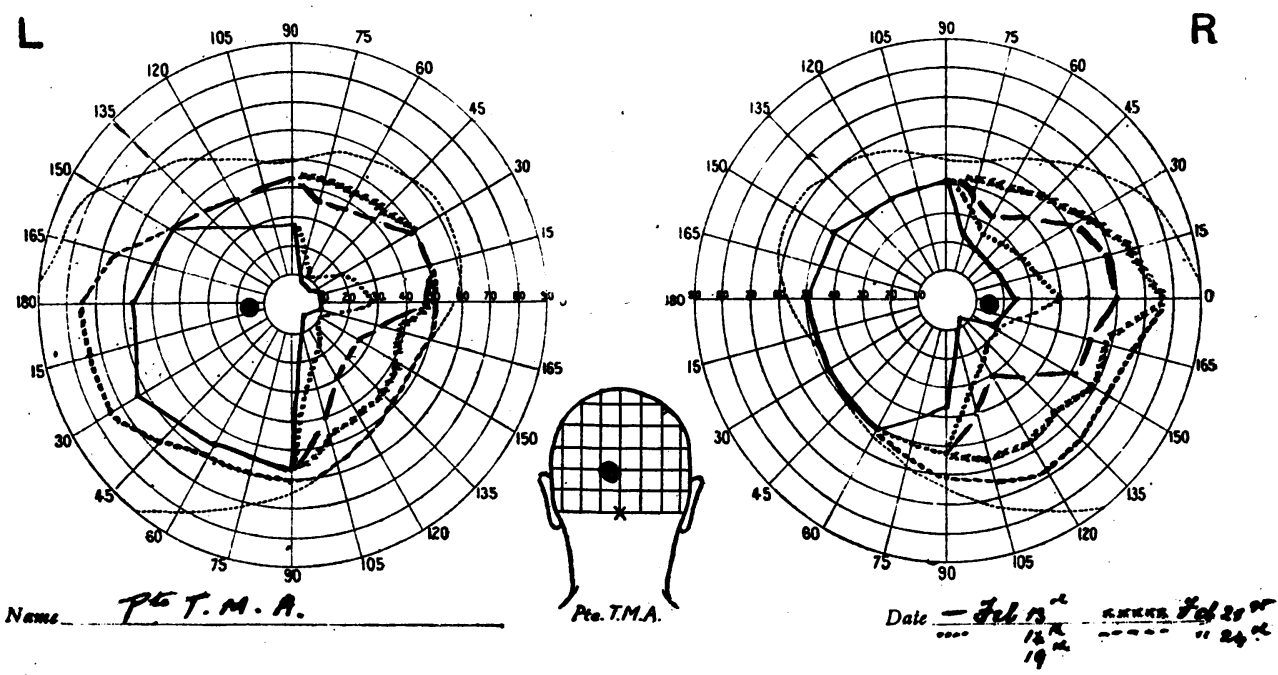

FIG. 1.

The next day the fields were again taken, showing a slight extension to the right with an exaggeration of the horizontal peak. The patient remained in exactly the same condition for five days, having a good deal of headache, and a slight pyrexia up to $100^{\circ} \mathrm{F}$, accounted for by a slight superficial suppuration of the scalp wound. On February 19 he was improving and had less headache, the temperature had fallen to normal, and the fields to the right had considerably increased, still extending furthest in the horizontal meridian. Two days later the peak had become flattened by an extension of the field above and below, and again three days later, on February 24, thirteen days after the injury and eleven days after the operation, a slight further extension was noted, making the fields almost full. No further change was noted till March 3, when the patient was evacuated to England. There was always an appreciation of colour in the gradually returning field in this patient, liut I did not make any careful tests with smaller objects in this case. 
Case 2.-Corporal S. had an injury very similar to the above, but his chart shows a more characteristic complete hemianopia at the first examination, and a more steady recovery, while he also shows the later return of the field in the lower quadrant, which seems to be most usual.

His injury was received on April 24, the wound being above and to the right side of the occipital protuberance, about $1 \frac{1}{2}$ inch. $\mathrm{He}$ was first seen on April 28, when he was found to have a complete left hemianopia, the macular area being carefully tested with a $2 \mathrm{~mm}$. test object (Fig. 2). Operation that afternoon revealed a
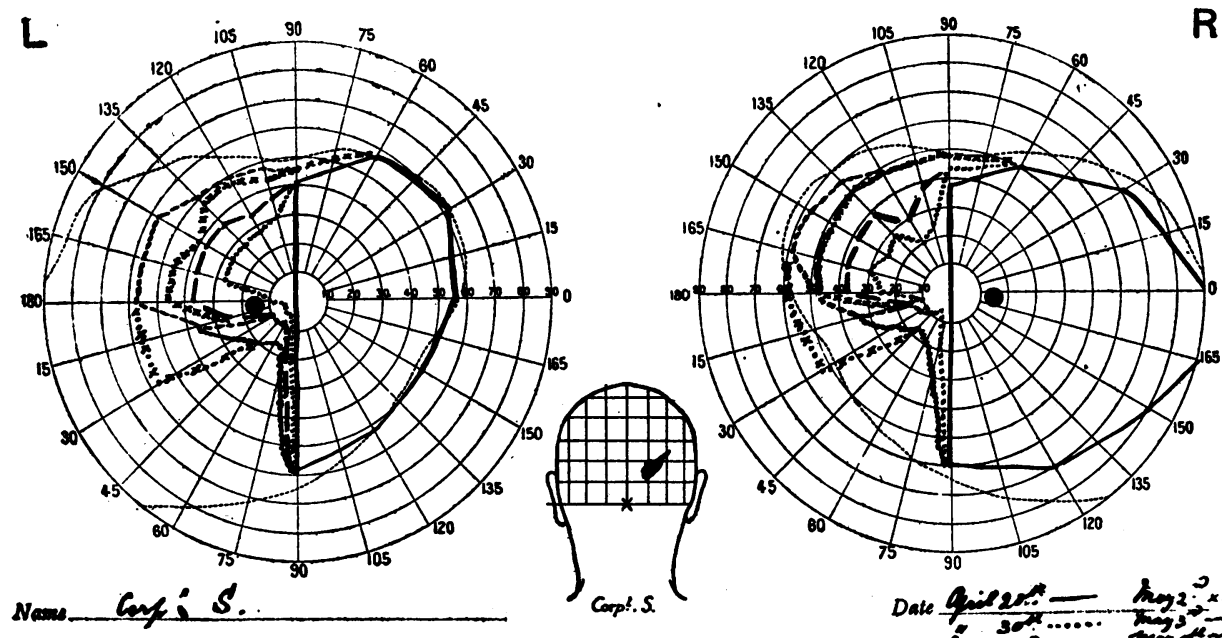

FIG. 2.

fracture of the right occipito-parietal region, and trephining showed blood clot under an unopened dura on the right side. The wound was then partly closed, and two Carrel's tubes were inserted.

The following day the patient had severe headache, but no change was found in the fields, the hemianopia being complete to the left. The next day there was a definite extension of the fields to as far as $30^{\circ}$ in the left upper quadrant, with very slight extension in the left lower quadrant. This extension gradually increased till May 3 in the upper quadrant, but very slightly in the lower until May 8, when these fields showed a definite increase, extending to as far as $55^{\circ}$ from fixation point in the upper part, still leaving a sector-shaped gap between $30^{\circ}$ and the vertical meridian. A rough examination limited to the naming of $10 \mathrm{~mm}$. and $5 \mathrm{~mm}$. coloured objects in the various quadrants did not detect any defect in the colour vision in the returning fields at that time. Unfortunately, I then missed the patient by coming home on leave, and was unable to trace where he had been sent on my return, so that I cannot say 
whether he ultimately recovered the full field in the left lower quadrant.

Case 3.-Private P. was injured on the back of the head by the bursting of a German shell while he was in the trenches on February 13, 191\%. He suffered from concussion and could not remember anything till he arrived in hospital on February 15, when I examined him. The next day he told me that this was the first thing he remembered since his injury. He was in a dazed condition and complained of headache, so again it was impossible to prolong the examination, and the field of the left eye
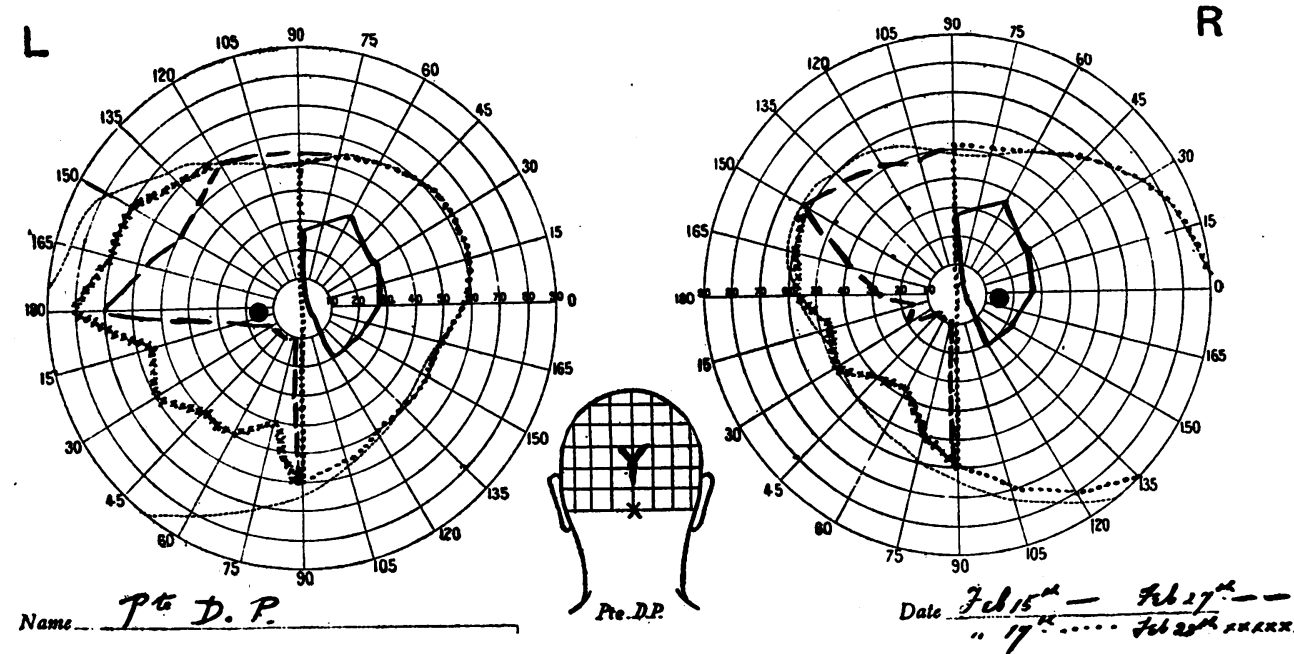

FIG. 3

only was taken. He was unable to fix well, and his central vision was blurred and indefinite just to the right of fixation point, and completely absent to the left. The field obtained was entirely to the right and very small, its furthermost limit being $35^{\circ}$ from fixation point along the meridian $60^{\circ}$ up and out. The next day he had considerable headache and was not examined, but the following day the field to the right was completely restored as far as the test then made detected ; i.e., examination with $10 \mathrm{~mm}$. and $5 \mathrm{~mm}$. white objects, and the naming of similar coloured objects. There was a complete hemianopia to the left, including the macular area (Fig. 3). Examination of the optic discs showed slight blurring of the edges, and some tortuosity of the veins. Pulse rate 40.

The patient remained in the same condition without any alteration in his fields till February 27, i.e., fourteen days after the injury, when he had a very intense occipital headache in the morning, and in the afternoon showed a returning field on the left, almost limited 
to the upper quadrant. His answers were extremely variable; several examinations in the same meridian giving different results, usually a smaller field at the later test, but there was definitely very little field in the left inferior quadrant. The replies to tests on the fields to the right were quick and accurate, making it evident that the cause of the variability to the left was local and not general. There was no appreciation of colour to the left, $10 \mathrm{~mm}$. coloured objects being used, while $2 \mathrm{~mm}$. coloured objects were clearly seen to the right.

The following day the patient was much more definite in his replies to tests on the fields to the left, although not quite as certain as on those to the right, and there was a definite increase in the left inferior quadrant. Colour appreciation had now definitely returned in both upper and lower left quadrants, although unfortunately, the testing was not as complete as in the case next recorded.

The patient was in this condition when he was evacuated to England. His scalp wound was $1 \frac{1}{2}$ inches above the occipital protuberance in the middle line. No fracture was ever found and no operation was performed, and, beyond the original concussion, all his symptoms were referable to the injury to his occipital cortex, whatever its nature. It did not clear up in the gradual way one would now associate with cases of sub-dural haemorrhage and slow absorption of the clot, as in the two previous instances; but, when once the improvement started it was rapid, as in the purer concussion cases. The length of time the complete haemianopia lasted, viz., 14 days from the injury, would seem to indicate some intracranial haemorrhage, however, especially as there was originally a little blurring of the optic discs which subsided. The pulse rate never increased beyond 64 .

Case 4.-Private R. D., who was wounded just above and to the right of the occipital protuberance at 10 p.m. on June 6, 1917, was perhaps the purest case of concussion injury of the series. Operation, at which the scalp wound was excised and sutured, revealed no fracture visible externally, while a skiagram taken beforehand was a little doubtful, the possibility of a fractured inner table being present. There was no sign of any optic neuritis. The patient was first examined at 10 a.m. on June 8, i.e., 36 hours after the injury. He was quite sensible and complained only of some headache and defective vision. His fields showed an absolute left hemianopia, including the macular area, which again was accurately tested with a $2 \mathrm{~mm}$. object on a modified Bjerrum's screen at $50 \mathrm{~cm}$. (Fig. 4). Operation was performed that afternoon, as above described. The following day, at 3 p.m., there was a returning field in the left upper quadrant for a $10 \mathrm{~mm}$. white object on the hand perimeter and a $5 \mathrm{~mm}$. white object was seen as well as a $10 \mathrm{~mm}$., but no colour was appreciated even in $10 \mathrm{~mm}$. objects. The answers given 
were not very accurate or constant, the patient readily tiring, although the fields to the right remained constant.

On June 10 , at 3 p.m., the fields in the left upper quadrant were full to a $10 \mathrm{~mm}$. white object, and colours were now appreciated, while a $2 \mathrm{~mm}$. white object was clearly seen, but was said to appear much sharper to the right. The left lower quadrant now showed practically full fields for a $10 \mathrm{~mm}$. white object, but a $5 \mathrm{~mm}$. white object was not distinguished except on movement, and a $2 \mathrm{~mm}$. white object was not seen at all, even on movement, until almost on fixation point. At $\frac{1}{2}$ metre only the movement of a

$L$

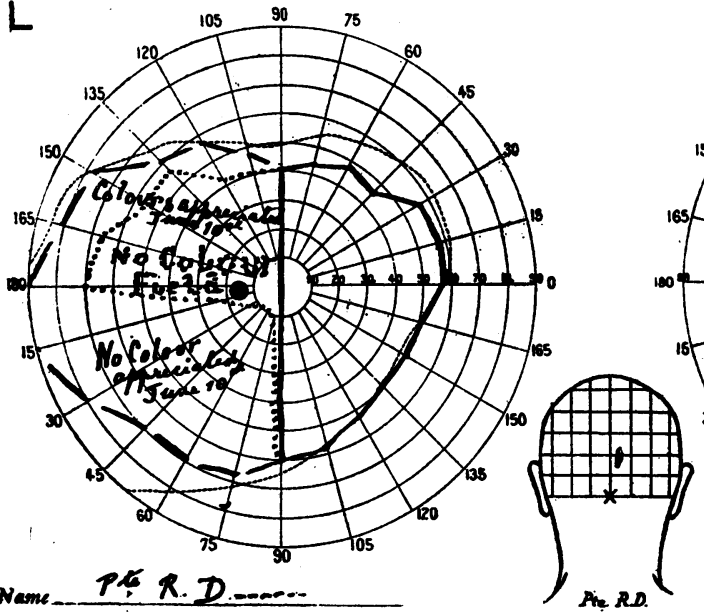

FIG. 4.

$10 \mathrm{~mm}$. object was appreciated in the left lower quadrant, while there was no appreciation of colours at all.

On June 11, at 3 p.m., in the left upper quadrant a $5 \mathrm{~mm}$. coloured (red) object placed $7 \mathrm{~cm}$. from fixation point was appreciated at 1 metre distance, while in the fields to the right it was distinguished at 3 metres or more. In the left lower quadrant $5 \mathrm{~mm}$. coloured objects were not appreciated beyond $30 \mathrm{~cm}$., but a $2 \mathrm{~mm}$. white object was seen and distinguished beyond that distance, although less clearly than in the upper quadrant.

On June 12 no change. was noted.

On June 13, patient could distinguish a $5 \mathrm{~mm}$. coloured object in left upper quadrant at 3 metres, and could appreciate very little, if any, difference himself between his clearness of vision in that quadrant and that to the right. In the left lower quadrant he could distinguish a $5 \mathrm{~mm}$. red object at $1 \frac{1}{2}$ metres, but not beyond, and he could still see a $2 \mathrm{~mm}$. white object more clearly in the upper than in the lower quadrant. 
The patient's symptoms having now disappeared, and his general condition being very satisfactory, he was evacuated to England, and it would seem probable that the recovery of function ultimately would be complete, although possibly an extremely patient search with small enough coloured objects at varying distances might detect small differences from the normal in the left lower quadrant. It is interesting to note that after June 11 the patient himself made no complaint of defective vision, and stated that objects looked natural to him, so that only a careful clinical examination at this period of recovery could detect that there had been any cortical injury, either gross or microscopic. His headache had entirely disappeared, and he seemed normal, but did not tolerate a long examination-hence, it was not possible to chart the relative macular quadrantic scotoma that evidently existed at one time, and the easier, although less accurate method of varying the distance of the test object was tried.

Case 5.--Private H. was hit by fragments of H.E. shell on July 31 while digging in an advanced position. Holes were made in his shrapnel helmet, and in hospital two fragments of metal were removed from his scalp. The first wound was the deeper, $1 \frac{1}{2}$ inch above the occipital protuberance, on the right side, $30^{\circ}$ from the vertical, and later, at operation, a tiny depressed fracture, the size of a threepenny piece of outer table and of one shilling of inner table was found beneath the wound, with a small extra-dural haemorrhage. The dura was unopened and was pulsating well. The second wound was superficial, $2 \frac{1}{2}$ inches above the inion on the left sice, $15^{\circ}$ from the vertical.

After the injury, patient was unconscious for a few minutes. $\mathrm{He}$ was then helped back to the dressing station. He noticed that he could only see " half of things," and that his vision was blurred.

Examined on August 2 at noon, he thought his vision was improving a little, but complained that things to the left were very blurred. His fields for $10 \mathrm{~mm}$. white were as shown on the chart (Fig. 5). Colour appreciation was present in the macular area in all quadrants. There was considerable headache, but no optic neuritis.

On August 3 no change was noticed in the fields.

On August 4, patient had less headache and was reading the newspaper. The fields were increasing, although the increase to the left was much more marked in the left eye than in the right, the result being checked three or four times. In the left eye the field tor white was almost full in the left upper quadrant, and increasing in the left lower quadrant. Definite blurring of vision was noticed by the patient in the left lower quadrant ; $5 \mathrm{~mm}$. red object distinguished in a poor light at $20^{\circ}$ from fixation point on perimeter in all other quadrants, but at $12^{\circ}$ in the left lower quadrant.

On August 6 operation showed the condition recorded previously. 
On August 7 the fields in left lower quadrants were somewhat increased, but objects still seemed more blurred to patient in this quadrant. In better light $5 \mathrm{~mm}$. red object appreciated at $30^{\circ}$ from fixation point in left upper and both right quadrants, and at $15^{\circ}$ in left lower quadrant. There was no difference between quadrants in the distance from the eye at which $5 \mathrm{~mm}$. coloured objects were appreciated.

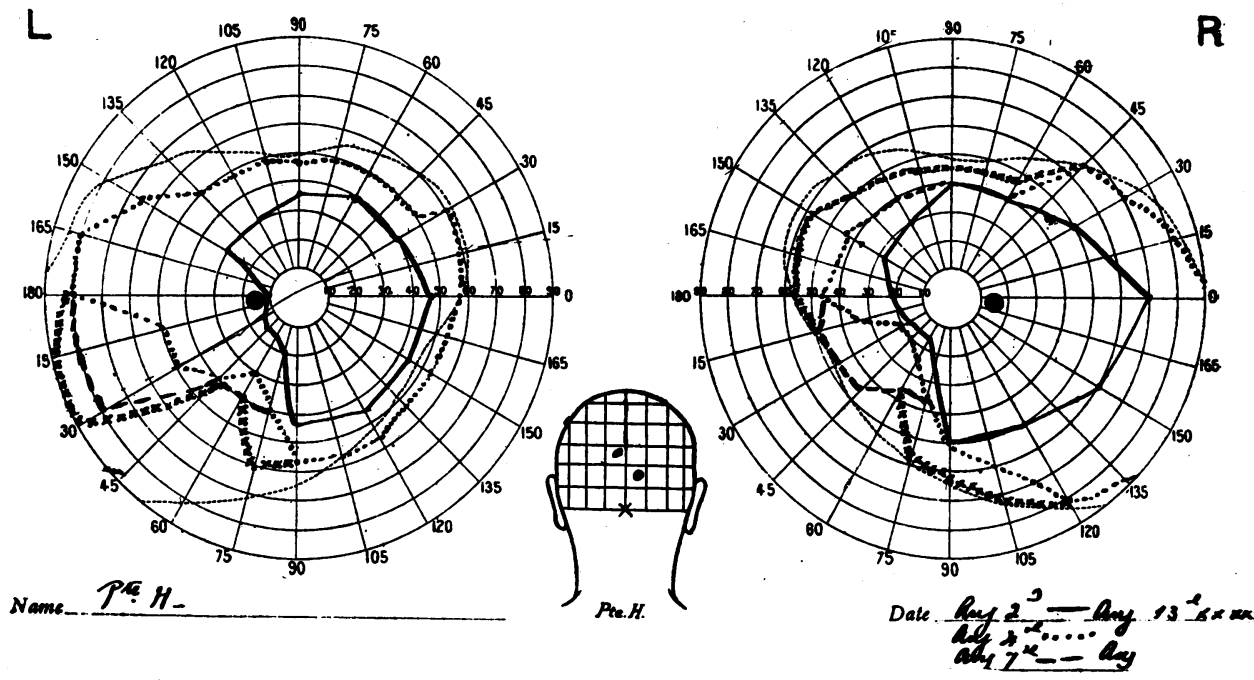

FIG. 5.

On August 13 there was a small increase in the left lower quadrant, making the field in the right eye practically full, but showing in the left eye a sector gap between $30^{\circ}$ and $75^{\circ}$ meridians, extending from the periphery to $40^{\circ}$ from fixation point.

Patient was now evacuated to England, and I have as yet obtained no particulars about his fields of vision.

Case 6.--Private D., wounded on July 29 while going to relieve another battalion. Was unconscious for one hour, then was helped up, and walked by himself to advanced headquarters, where he rested for an hour. He then walked by himself to field dressing station and thence to F.A.; and could see quite well enough to find his way without much difficulty. From the F.A. he was a stretcher patient to C.C.S. and base.

When seen at 9 p.m. on July 30 he said his sight had improved a little. He complained of occipital and frontal headache. There was no optic neuritis. On rough testing there was central vision only.

The next morning, July 31, examination showed a wound of the scalp extending from $2 \frac{1}{2}$ inches above the occipital protuberance upwards, and slightly to the left for 2 inches. There was no optic 
neuritis, and X-ray examination subsequently showed no evidence of fracture.

For a $10 \mathrm{~mm}$, white object at $50 \mathrm{~cm}$., there was macular vision only, extending $2^{\circ}$ from fixation point with either eye. Hand movements were appreciated about $30^{\circ}$ from fixation point. The colour of a large $40 \mathrm{~cm}$. red and green object was appreciated at fixation point, but a $10 \mathrm{~mm}$. red object was said to be "bluish green," and a $10 \mathrm{~mm}$. green object " pale green."

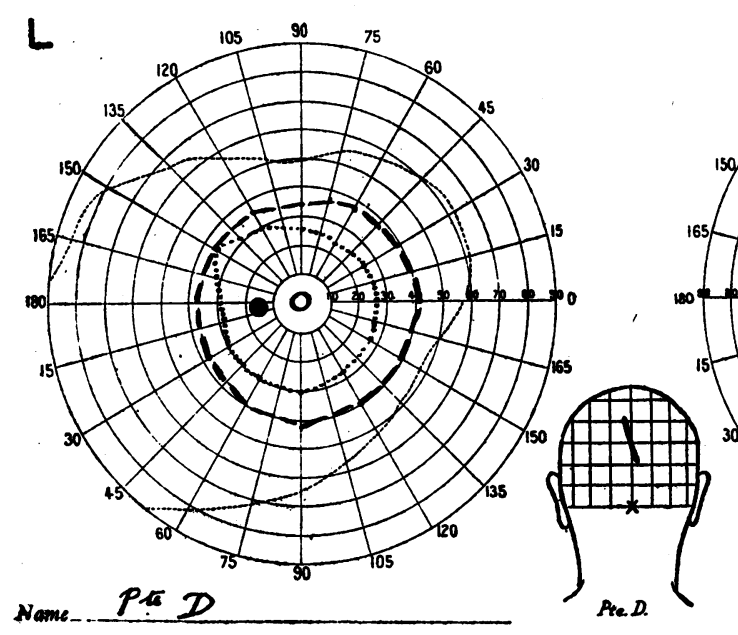

FIG. 6.

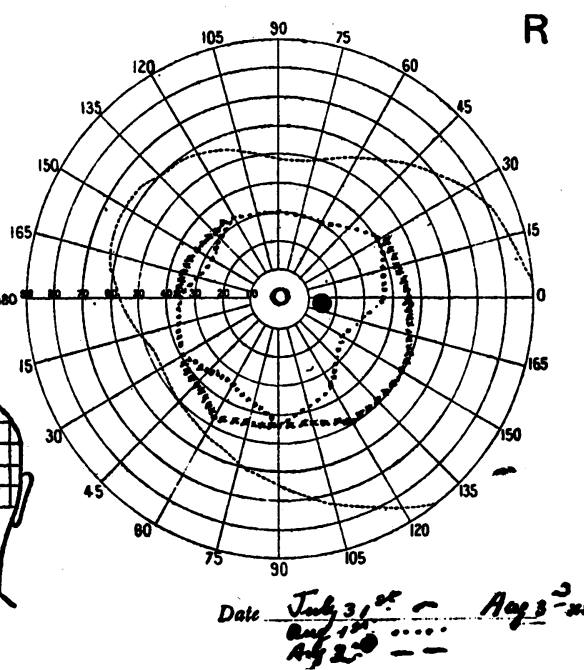

$\mathbf{R}$

On August 1, patient noticed his vision was improving. The fields for $10 \mathrm{~mm}$. white had definitely increased fairly symmetrically about fixation point - extending to $25^{\circ}-35^{\circ}$, while hand movements were appreciated about $50^{\circ}$. Colours were appreciated in the returning fields, no difference being noticed in any quadrant. Patient readily tired. The field of the left eye was taken after that of the right.

On August 2, the field of the left eye taken before that of the right, showed some increase, but the right remained stationary.

On August 3, there was slight increase noted in field in right eye, especially below, making it symmetrical with the field of the left eye which was unaltered. No difference in appreciation of colour can be detected in any quadrant. Patient can read J. 1 a few words at a time. He still readily tires.

No further change was noted in the fields of vision during the next twelve days. Patient still complained of headache and readily tired. Lieut.-Col. Gordon M. Holmes, who saw the patient at this time, regarded the contraction of the fields from the commencement of observation as probably a functional condition, and it would be 
difficult to explain on any other supposition, the history also being taken into account. In my opinion, this is the case which most closely corresponds with the one recorded in Kinnier Wilson's paper, and it has been included in this series for purposes of comparison.

Case 7.-Private G. is recorded here, not as a pure concussion injury-as in his case there was a depressed fracture and a penetrating wound of the dura with laceration of a yery small area of the brain substance-but rather to show the importance of careful examination, if recovering cortical lesions, which have not been watched from the outset, are not to be missed.

This patient was wounded on July 3, and arrived at the Base Hospital on July 4, with a small wound, apparently superficial, a little above and to the left of the occipital protuberance.

The injury occurred while the patient was in a trench, from the bursting of a H.E. shell, and he remembered falling over, trying not to lose consciousness, and being picked up by his mate in the same place a few minutes later. He walked to the dressing station, went as a sitting case to the C.C.S., whence he was evacuated as a stretcher case. He was able to see big objects, and did not notice anything wrong with his vision, but, as he had considerable headache, he did not look about him much. After admission to hospital at the base he noticed that he could not see things quite plainly in froht of him, which he found out by looking at the number of the bed opposite. $\mathrm{He}$ also had difficulty in reading, though he could read J.1, a few words at a time.

The vision of his right eye seemed to him worse than that of the left, but he was not very sure that this had not always been the case. On July 10 the wound was explored under local anaesthesia, and a tiny piece of H.E. was removed, while to the surprise of the surgeon, a small depressed fracture was found underneath. At this time I was asked to see the patient, as more notice was now taken of his subjective visual symptoms, and found the condition stated below. The next day, July 11, under a general anaesthetic, a small depressed fracture was raised, the dura being penetrated beneath and a small area of brain substance lacerated, $1 \frac{1}{2}$ inch above and to the left of the occipital protuberance, at an angle of $30^{\circ}$ from the vertical.

Examination of the eyes on July 10 showed no evidence of optic neuritis, past or present. The fields were quite full for a $10 \mathrm{~mm}$. white object on a hand perimeter. The right field showed a partial colour scotoma in the lower quadrant, a $10 \mathrm{~mm}$. object red, green, or blue, not being distinguished till almost on fixation point, this being much more marked in the right eye than in the left. With a modified Bjerrum's screen at 1 metre distance in the right eye, a $10 \mathrm{~mm}$. coloured object was seen just before fixation point in the right lower quadrant-a $5 \mathrm{~mm}$. coloured object was not 
appreciated until right up to fixation point, while a $5 \mathrm{~mm}$. white object was seen much better to the left than to the right. In the right upper quadrant no difference was noticed by the patient for a $5 \mathrm{~mm}$. white object as compared with the left side, but a $5 \mathrm{~mm}$. coloured object was a little clearer on the left side than on the right. The same applied to the field in the left eye, except that the scotoma in the right lower quadrant was even less marked, as $5 \mathrm{~mm}$. coloured objects were recognized $2 \mathrm{~cm}$. from fixation point, although neither as clearly, nor as far from fixation point as to the left nor in the right upper quadrant.

A week after operation the vision had improved, and all $5 \mathrm{~mm}$. coloured objects were recognized in the right lower quadrant as well as to the left, at the same distance from fixation point and at the same distance from the eye. The patient was then evacuated to England.

Though the cases are few in number, they seem to suggest certain conclusions, some of which have previously been reached by others, most recently by Colonel Lister and Lieut.-Colonel Gordon M. Holmes in their paper on "Disturbances of Vision from Cerebral Lesions with special reference to the Cortical Representations of the Macula."

1. In the case of an injury at or near the occipital pole the hemianopia is very frequently complete, there being much less frequently macular escape than in the majority of cases with lesions (chiefly vascular) producing hemianopia, met with in civil practice. This is explained in the paper mentioned above as being due to the situation of the macular area in the cortex at the posterior end of the calcarine fissure, by the occipital pole, each half of the macula being represented on one side only, the right half of each macula in the right cortex and the left half in the left. The more usual escape in civil practice is attributed to an overlapping of the arterial supply by the posterior and middle cerebral vessels.

2. The visual fields are gradually restored by recovery from centre to periphery. It may be noted that a scotoma caused by loss of cerebral substance gradually contracts from periphery to centre as the surrounding oedema of the brain subsides.

3. The field of vision usually returns in the upper quadrant before the lower, and, in my experience, never vice versa, this being due to the fact that all the injuries recorded here have been above the occipital pole, which is situated as a rule about 1 inch above the inion. Hence, the occipital cortex above the calcarine fissure, which represents the lower. part of the field of vision, has borne the brunt of the blow. Any injury below the occipital protuberance is much more likely to be fatal, owing to injury to the cerebellum and medulla, as pointed out by Colonel Lister and Lieut-Colonel Gordon M. Holmes, who have seldom obtained a record of a patient showing a superior quadrantic macular defect. 
I have not been able to obtain a case of injury to the occipital cortex from contre-coup for investigation, and do not know whether such a case has occurred.

4. The restoration of function at first is incomplete, but when once it has commenced it seems to proceed in a definite ordercolour perception coming after the perception of white, even though the coloured object is the larger, and, as recovery takes place the appreciation of colours becomes more and more acute, so that small coloured objects can be distinguished further and further away. By this means, in suitable cases, one can roughly measure for clinical purposes the recovery of function in the macular area, and make comparison between the various quadrants affected, more elaborate and lengthier tests being as a rule impracticable with these patients.

5. This being so, and especially having regard to the seventh case quoted, it is important, when investigating any patient suspected of having had an occipital cortical injury, to use small coloured test objects as well as the white, or a partially recovered lesion may quite readily be missed and the fields found to be full. This is the more important when one realizes how completely even a gross injury of the cerebral substance may clear up, and leave no trace behind. If this fact is borne in mind, I believe that quite a number of overlooked lesser injuries to the cerebral cortex of the occipital lobe (which could be classed as "concussion" or "contusion injuries" as Kinnier Wilson would prefer to call them), will be discovered.

6. On the other hand, in the more slowly and steadily recovering cases with subdural or extradural haemorrhage, there would seem to be no such separation between colour appreciation and appreciation of a white test object. This could be explained by supposing a less severe injury to the macular area, while only a careful comparison of the colour fields from day to day could show whether they increased proportionally to the fields for white. Such examination in almost all cases would be impossible on account of the patient's condition, and in the great majority of cases it would anyhow be unreliable.

In conclusion, I should like to express my thanks to Colonel Lister and Lieut.-Colonel Holmes for encouragement while making these observations, and to the various medical officers who have given me opportunities for investigating suitable patients. Beyond the two papers mentioned, I have been unable to look for literature on the subject, but both papers contain a good bibliography.

\section{REFERENCES}

Wilson, S. A. Kinnier.-Lancet, July 7, 1917. Trans. Ophtinal. Soc., 1917, p. 92. Lister and Holmes, Gordon M.-Proc. Roy. Soc. Med., Vol. IX, 1916. 